\title{
Overproduction of Corticotropin-releasing Factor in Transgenic Mice: A Genetic Model of Anxiogenic Behavior
}

\author{
Mary P. Stenzel-Poore, ${ }^{1}$ Stephen C. Heinrichs, ${ }^{2}$ Serge Rivest, ${ }^{1}$ George F. Koob, ${ }^{2}$ and Wylie W. Vale ${ }^{1}$ \\ ${ }^{1}$ Clayton Foundation Laboratories for Peptide Biology, The Salk Institute for Biological Studies and ${ }^{2}$ Department of \\ Neuropharmacology, The Scripps Research Institute, La Jolla, California 92037
}

\begin{abstract}
Corticotropin-releasing factor (CRF) is released in response to various stressors and regulates adrenocorticotropin secretion and glucocorticoid production. In addition to its endocrine functions, CRF acts as a neuromodulator in extrahypothalamic systems and has been shown to play a role in behavioral responses to stress. CRF overproduction has been implicated in affective disorders such as depression and anorexia nervosa. A transgenic mouse model of CRF overproduction has been developed in order to examine the endocrine and behavioral effects of chronic CRF excess. CRF transgenic animals exhibit endocrine abnormalities involving the hypothalamic-pituitary-adrenal axis such as elevated plasma levels of ACTH and glucocorticoids. The present series of experiments tested the hypothesis that chronic overproduction of CRF throughout the life-span of these animals may lead to an anxiogenic behavioral state. CRF transgenic mice and normal littermate controls were tested by measuring locomotor activity in a novel environment and through the use of an elevated plus-maze as indices of anxiety. CRF transgenic animals exhibited an increase in anxlogenic behavior, an effect known to occur following central administration of CRF in mice and rats. Injection of the CRF antagonist $\alpha$-helical CRF 9-41 into the lateral cerebral ventricles reversed the anxiogenic state observed in the CRF transgenics. This finding supports the possibility that central CRF overproduction may mediate the anxiogenic behavior exhibited in this animal model. Thus, CRF transgenic mice represent a genetic model of CRF overproduction that provides a valuable tool for investigating the long-term effects of CRF excess and dysregulation in the CNS.
\end{abstract}

[Key words: ACTH, anxiogenic, behavior, corticotropin-releasing factor, depression, glucocorticoids, rodents, transgenic]

Corticotropin-releasing factor (CRF) is a 41-residue hypothalamic peptide that stimulates the secretion and biosynthesis of pituitary ACTH leading to increased adrenal glucocorticoid production. CRF was originally isolated and characterized on the basis of this role in the hypothalamic-pituitary-adrenal (HPA)

\footnotetext{
Received May 4, 1993; revised Sept. 17, 1993; accepted Oct. 14, 1993.

We acknowledge Dr. Peter Stenzel and Kurt IIeldwein for their generous help in these studies. This work was supported by NIH Grants DK-26741, NIAAA $07456 / 06420$ to the Alcohol Research Center of the Scripps Research Institute, and NIH fellowship DK-08385 (M.S-P.) and the Kleberg Foundation (M.S-P.).

Correspondence should be addressed to M. P. Stenzel-Poore, Department of Microbiology and Immunology, Oregon Health Sciences University, 3181 Sam Jackson Park Road, Portland, OR 97201.

Copyright (C) 1994 Society for Neuroscience $0270-6474 / 94 / 142579-06 \$ 05.00 / 0$
}

axis (Vale et al., 1981). More recently, however, CRF has been found to be distributed broadly within the CNS as well as in extra-neural tissues such as the adrenal glands and testes (Swanson et al., 1983; Suda et al., 1984; Fabbri et al., 1990), where it may also act as a paracrine regulator or neurotransmitter. In addition to its critical role of mediating HP $\Lambda$ axis activation, CRF has been shown to modulate behavioral changes that occur during the stress response. Many of these behavioral changes have been shown to occur independently of HPA activation in that they are insensitive to dexamethasone treatment and hypophysectomy (D. R. Britton et al., 1986; K. T. Britton et al., 1986a; Berridge and Dunn, 1989). In addition, direct infusion of CRF into the CNS mimics autonomic and behavioral responses to a variety of stressors (Sutton et al., 1982; Brown and Fisher, 1983; Stephens et al., 1988; Butler et al., 1990) and the peripheral administration of CRF or the CRF antagonist $\alpha$-helical CRF 9-41 has failed to produce these changes, thus supporting a central role for CRF in such functions.

Central administration of CRF in rodent animal models produces effects that correlate with a state of anxiety such as a reduction in investigation of unfamiliar surroundings (Sutton et al., 1982; Sherman and Kalin, 1987; Berridge and Dunn, 1989; Butler et al., 1990), decreased sleeping (Sherman and Kalin, 1987), enhanced fear responses (Sutton et al., 1982; Butler et al., 1990), decreased food consumption (Morely and Levine, 1982), and suppressed sexual behavior (Sirinathsinghji et al., 1983). These changes are similar to those behavioral changes that occur during acute and chronic stressors and parallel changes that occur in human affective disorders including major depressive disorder, panic disorder, and anorexia nervosa, suggesting a role for CRF in the pathophysiology of mental illness (Kaye et al., 1987; Gold et al., 1988b; Kathol et al., 1988; Nemeroff, 1988). CRF hypersecretion has been linked to a portion of those individuals diagnosed with major depression (Nemeroff et al., 1984) and while not all studies have supported the claim that cerebrospinal fluid CRF levels are altered in this group, most agree that HPA axis responsivity is abnormal and that a large portion of individuals diagnosed with depression have elevated cortisol levels (Roy-Byrne et al., 1986; Kling et al., 1991). Moreover, in major depression (Holsboer et al., 1984) and panic disorder (Roy-Byrne et al., 1986) CRF administration results in a blunted ACTH response, suggesting that the pituitary is properly restrained, presumably by the negative feedback effect of elevated levels of glucocorticoids. In view of these findings it has been suggested that the hypercortisolism in major depression is due to abnormal CRF secretion within the CNS (Gold et al., 1988a).

A transgenic mouse model of chronic CRF hypersecretion has 
recently been developed (Stenzel-Poore et al., 1992). These animals express high levels of $\mathrm{ACTH}$ and corticosterone throughout their life-span and develop a Cushing's syndrome phenotype due to cxccss glucocorticoid production. Numerous CNS sites in the transgenic animals display elevated CRF gene expression, although plasma CRF levels are not elevated (Stenzel-Poore et al., 1992). The fact that plasma levels do not parallel the increased expression of CRF in the brain may indicate that extra-hypothalamic sources of CRF transgene overexpression do not substantially contribute to plasma levels. In addition, since the CRF transgene is expressed in the pituitary, paracrine stimulation by locally synthesized CRF could provide a constant stimulus to corticotropes and result in elevated levels of ACTH without measurable changes in plasma levels of CRF. Thus, the fact that these animals show chronic overexpression of central CRF and hyperactivation of the pituitary-adrenal axis makes them a good model to investigate the role of CRF in long-term behavioral changes, particularly with respect to behavioral responses to stress.

In the present series of studies, the hypothesis that persistent central CRF hypersecretion produces anxiogenic behavior was tested. Measurements of behavioral responses to stress were made using two tests sensitive to the natural aversion of rodents for open spaces: the locomotor activity response in a novel environment and the elevated plus-maze (Pellow et al., 1985; Lister, 1987). The additive effect of social aggression on the performance of CRF transgenics was examined in order to determine the reactivity of these animals to a psychological stressor. Finally, to test whether brain CRF plays a role in mediating the altered behavior of the CRF transgenics, the protective actions of the centrally administered CRF antagonist $\alpha$-helical CRF 9-41 were examined.

\section{Materials and Methods}

\section{Animals}

CRF transgenic mice were generated as previously described (StenzelPoore et al., 1992). Briefly, the CRF transgene was composed of the rat genomic CRF gene (Thompson et al., 1987) and the 5' regulatory region was replaced by the mouse metallothionein-1 gene ( 1.8 kilobase pairs, kbp) (Palmiter et al., 1983). The 3' untranslated region of the human growth hormone gene $(0.65 \mathrm{kbp})$ that contains a polyadenylation signal sequence (DeNoto et al., 1981) was ligated to the 3' end of the CRF gene in order to ensure adequate RNA processing of the fusion gene. Transgenic mice $(\mathrm{C} 57 / \mathrm{B} 6 \times \mathrm{SJL})$ were screened using the polymerase chain reaction (PCR) and transgene-specific primers to amplify tail DNA as previously described (Stenzel-Poore et al., 1992). A single transgenic founder male was used as the source of this transgenic line and thus all animals are descendant offspring. Adult male mice (transgenic and nontransgenic littermate controls) aged 2-9 months and weighing 25-30 gm were housed singly in a pathogen-free transgenic facility. Mice were given rodent chow and water ad libitum and kept on a $12 \mathrm{hr}$ light/dark schedule with lights on from 0600 to 1800 .

Experiments involving animals werc performed in accordance with the NIH guidelines for care and use of laboratory animals.

\section{Surgery and intracerebroventricular microinjections}

Surgery. Mice were anesthetized with ketamine/xylazine $(50 \mathrm{mg} / \mathrm{kg}, \mathrm{sc})$ and mounted in a stereotaxic instrument with the incisor bar at -2.0 $\mathrm{mm}$. Mice were implanted with a single cannula placed in the right lateral ventricle. Guide cannulas $(2.5 \mathrm{~mm}$ length, 26 gauge; Plastics One, Roanoke, VA) were positioned $1.0 \mathrm{~mm}$ above the lateral ventricle (AP at the bregma; DV $1.4 \mathrm{~mm}$ below the surface of the skull and ML $1.1 \mathrm{~mm}$ lateral). The cannulas were fixed to the skull using three 1.6 $\mathrm{mm}$ stainless steel screws and dental cement. Animals were allowed to recover from surgery for a minimum of $5 \mathrm{~d}$ before testing, during which time 30 gauge dummy cannulas were left inside the guide cannula.

Brain cannula infusions. Intracerebroventricular (ICV) infusions were performed using 30 gauge infusion cannulas cut to extend $1.0 \mathrm{~mm}$ bcyond the end of the guide cannula. Dummy cannulas were removed and replaced by the infusion cannulas that were fitted to PE-50 tubing and connected to a $50 \mu \mathrm{l}$ syringe. The infusion samples were delivered in a $2.0 \mu \mathrm{l}$ volume over $30 \mathrm{sec}$ using an automated infusion pump. Infusion cannulas were left in place for an additional $60 \mathrm{sec}$ to prevent efflux of infusion material and then replaced by the dummy cannulas for the duration of the experiment. To verify cannula placements, the brains were removed, fixed in $10 \%$ formalin $10 \%$ sucrose, and frozen just prior to tissue sectioning on a freezing microtome.

\section{Behavioral tests}

Novel environment. A Plexiglas box $(33 \mathrm{~cm}$ long $\times 23 \mathrm{~cm}$ wide $\times 20$ $\mathrm{cm}$ high) was equipped with two computer-interfaced, infrared photocell beams that trisected the length of the chamber. Mice were allowed to explore the box for $30 \mathrm{~min}$, during which time horizontal locomotor activity as well as movement from one end of the box to the other was recorded. The boxes were cleaned with water following each use. Experiments designed to test the effect of social defeat stress were performed 3-5 min following exposure of the test animal to the stressor. The social defeat stress consisted of a bricf encounter betwecn a test male (intruder) and a resident male (resident) that has been housed with a family composed of a female and pups. The resident-intruder interaction took place in the resident male cage, and in all cases the intruder was placed in the cage for $<1 \mathrm{~min}$. At the first sign of aggressive behavior between two animals, the intruder male was removed from the resident cage and housed singly for 3-5 min before placement into the novel environment chamber to measure locomotor activity.

Elevated plus-maze. The elevated plus-maze was employed as a validated animal model of anxiety that is based on the natural aversion of rodents to open spaces and is a model that is sensitive to the effects of both anxiolytic and anxiogenic agents in rats and mice (Pellow et al, 1985; Lister, 1987; Onaivi et al., 1990). A four-arm radial maze consisting of two opposing enclosed arms $(30 \mathrm{~cm}$ high $\times 30 \mathrm{~cm}$ long $\times 5$ $\mathrm{cm}$ wide) and two opposing exposed arms $(30 \mathrm{~cm} \times 5 \mathrm{~cm})$ was elcvatcd on a pedestal $30 \mathrm{~cm}$ above the surface of a table and situated in the center of a dimly lit room. Computer-interfaced, infrared photocell beams siluated around the perimeter and diagonally across the center of the maze monitored the amount of time spent in each compartment and provided a gross measure of overall activity. Mice were placed in the center of the maze facing an enclosed arm to begin the 5 min test period and the apparatus was cleaned with wetted towels after each test. Tests involving brain cannula infusions were performed $5 \mathrm{~min}$ following the infusion of the test peptide or vehicle. The CRF antagonist $\alpha$-helical CRF 9-4l (J. Rivier, The Salk Institute) (Rivier et al., 1984) is a competitive antagonist of CRF that blocks endocrine, behavioral, and autonomic functions of CRF (Brown et al., 1986; Rivier et al., 1986; Berridge and Dunn, 1987; Kalin et al., 1988; Heinrichs et al., 1992). The $\alpha$-helical CRF 9-41 antagonist was dissolved in acidificd water $(\mathrm{pH}$ 6.7 ) and animals were infused with 1 or $5 \mu \mathrm{g}$ of $\alpha$-helical CRF in a $2 \mu \mathrm{l}$ volume or given vehicle alone $(2 \mu \mathrm{l})$.

\section{Experimental design}

All behavioral tests were performed in a dimly lit room between 1900 and 2400 during the active period of these animals. Two separate groups of mice were tested that had never experienced any form of behavioral testing prior to the studies described here. Group A was composed of 10 transgenic and 12 nontransgenic animals that were untreated, and group B consisted of animals ( 18 transgenic and 17 nontransgenic) that were cannulated intracerebroventricularly and used to examine the effect of $\alpha$-helical CRF 9-41. Both groups of mice were housed singly in microisolater cages. The mice were handled briefty the day prior to testing and the two behavioral tests were performed on separate days. The experiments were replicated twice using separate animals. Following a 2 month interval of no testing, a subset of group A mice (seven transgenic, six nontransgenic) were exposed to the resident-intruder social defeat stress and retested in the novel environment paradigm. The subset of mice had never previously been exposed to the residentintruder stress prior to this study.

ICV cannulations were performed on group B animals 1 week prior to behavioral testing. Infusions were performed in the home cage. At the time of testing, the dummy cannula was removed and replaced with the infusion cannula. Vehicle or $\alpha$-helical 9-41 CRF was slowly delivered in a $2.0 \mu \mathrm{l}$ volume over a $30 \mathrm{sec}$ interval. To avoid leakage of the infusion 

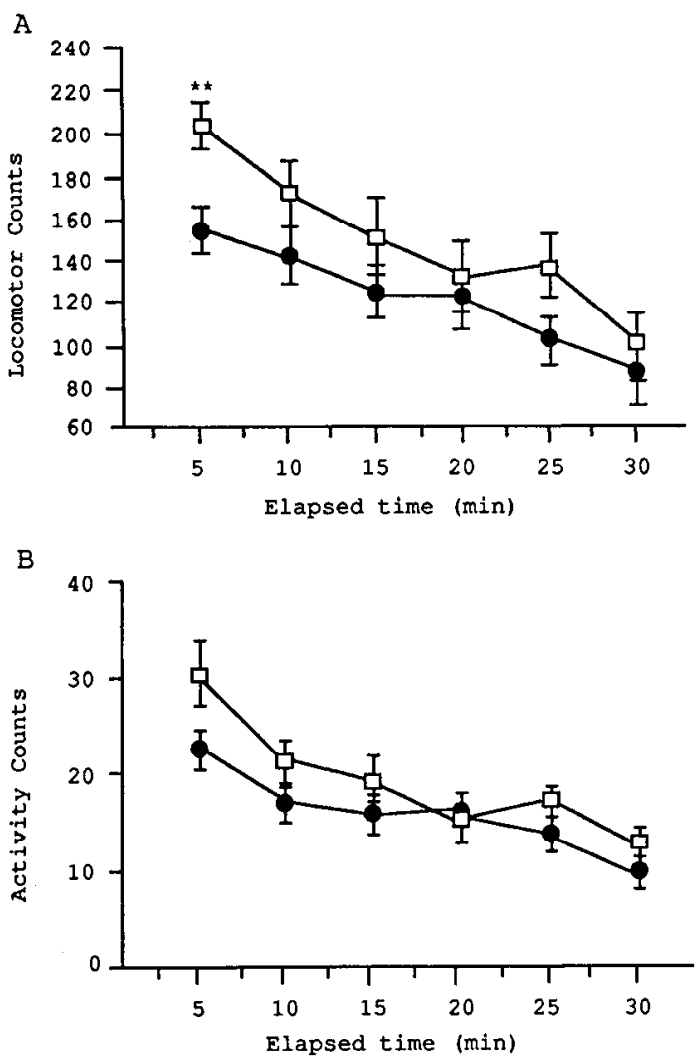

Figure 1. Mean ( \pm SEM) locomotor activity $(A)$ and crossover frequency $(B)$ of control (squares; $n=10$ ) and transgenic CRF (circles; $n$ $=12$ ) mice placed individually for $30 \mathrm{~min}$ in novel photocell cages. ${ }^{* *}$, $p<0.01$.

material, the infusion cannula was left in place for an additional $60 \mathrm{sec}$ and then replaced with the dummy cannula. Treated animals were tested on the elevated plus-maze $5 \mathrm{~min}$ following the ICV infusion.

\section{Statistical analysis}

The overall two- and three-factor designs were analyzed by ANOVA with transgenic status and peptide treatment as between-subject factors and elapsed time as a repeated measure. Individual means $( \pm$ SEM) were compared using Newman-Keuls post hoc and Student's $t$ tests.

\section{Results}

Behavior of the CRF transgenics differed markedly from control animals in test situations designed to assess behavioral activation and anxiogenic-like states.

\section{Novel environment}

Locomotor activity varied significantly $[F(5,100)=19.29, p$ $<.001]$ with elapsed time, as did crossover activity $[F(5,100)-$ $25.73, p<.001]$. Analysis of simple main effects indicated that CRF transgenic mice were less active during the first $5 \mathrm{~min}$ of the test $(p<0.01$, Newman-Keuls test) but did not differ significantly from nontransgenic littermate controls at any subsequent $5 \mathrm{~min}$ interval up to $30 \mathrm{~min}$ (Fig. 1).

\section{Effects of social defeat on locomotor activity in the novel environment}

Assessment of locomotor activity in the novel environment showed a clear reduction in locomotion among transgenic animals compared to controls. To test whether this behavioral difference could be exaggerated by social defeat stress, animals
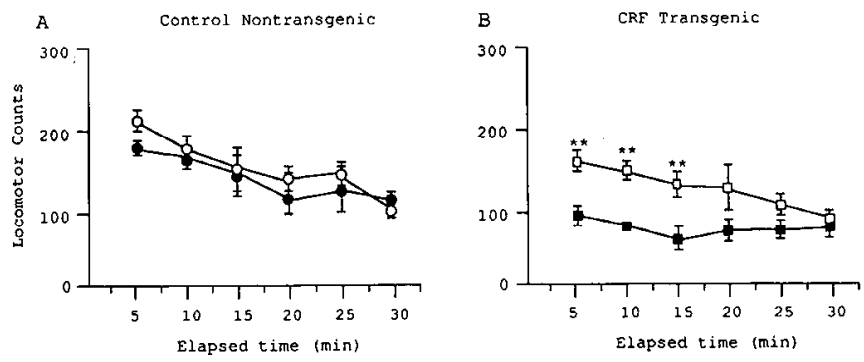

Figure 2. Mean ( \pm SEM) locomotor activity of untrcatcd (open circles; $n=10$ ) versus prestressed (solid circles; $n=6$ ) control mice $(A)$ and untreated (open squares; $n=12$ ) versus prestressed (solid squares; $n=$ 7) CRF transgenic mice $(B)$. Activity of individual mice was measured in novel photocell cages over a 30 min test period. ${ }^{* *}, p<0.01$ versus prestressed CRF transgenic mice.

were tested in the novel environment immediately following social defeat by an aggressive male counterpart mouse. A significant effect was observed during the first $15 \mathrm{~min}$ of testing wherein transgenic animals were markedly hypoactive compared with prestressed transgenics (Fig. 2).

\section{Elevated plus-maze}

The percentage of time spent on exposed versus enclosed arms $[F(1,16)=4.56, p<0.05]$ and the overall activity $[F(1,16)=$ $7.53, p<0.02]$ were significantly reduced among CRF transgenic mice relative to controls (Fig. 3 ).
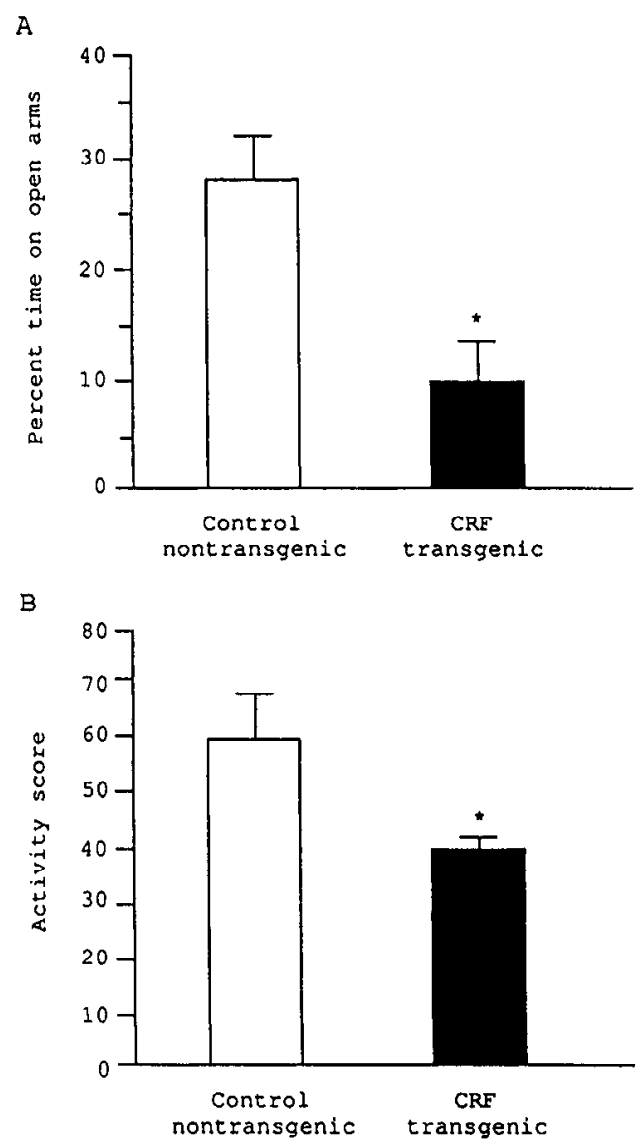

Figure 3. Mean (+SEM) percentage of time spent on the open arms $(A)$ and overall activity $(B)$ of control $(n=8)$ or CRF transgenic $(n=$ 10) mice over a $5 \mathrm{~min}$ test on the elevated plus-maze. ${ }^{*}, p<0.05$. 
A

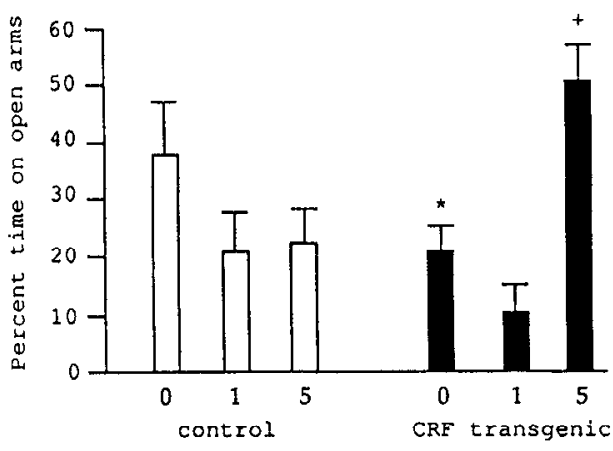

$\alpha$-helical CRF 9-41 (ug ICV)

B

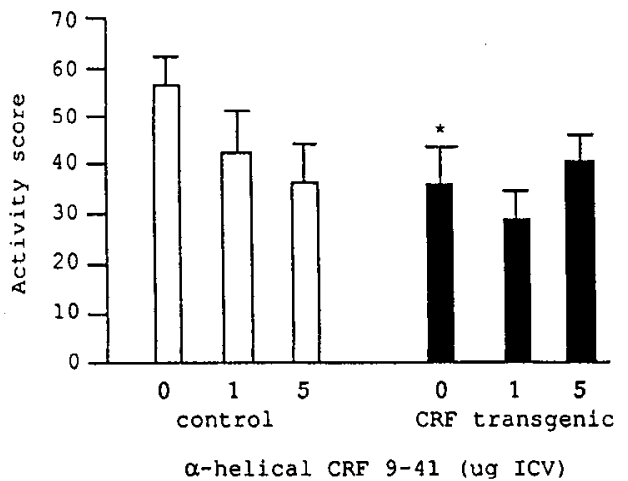

Figure 4. Mean (+SEM) percentage of time spent on the open arms $(A)$ and overall activity $(B)$ during a 5 min test on the elevated plusmaze following pretreatment with CRF antagonist of both control $(0$, $n=7 ; 1 \mu \mathrm{g}, n=5 ; 5 \mu \mathrm{g}, n=5)$ and CRF transgenic $(0, n=7 ; 1 \mu \mathrm{g}, n$ $-5 ; 5 \mu \mathrm{g}, n=6)$ mice. Statistical significance determined by Student's $t$ test; ${ }^{*}, p<0.05$ versus vehicle-treated control group;,$+ p<0.05$ versus vehicle-treated CRF transgenic group.

\section{Effect of ICV administration of $\alpha$-helical CRF 9-4I on the elevated plus-maze}

The effect of ICV administration of $\alpha$-helical CRF 9-41 was tested using the elevated plus-maze as a measure of anxiogenic behavior since this test is exquisitely sensitive to CRF agonist and antagonist effects (Heinrichs et al., 1992; Pich et al., 1993). The reduced time spent on the open maze arms in vehicletreated CRF transgenic mice relative to vehicle-treated controls $[t(12)=1.8, p<0.05$, one-tailed] was completely reversed by ICV infusion of the CRF antagonist $\alpha$-helical CRF 9-41 at a dose of $5 \mu \mathrm{g}[F(1,12)=17.2, p<0.005]$ but not $1 \mu \mathrm{g}, 5 \mathrm{~min}$ prior to testing on the elevated plus-maze (Fig. $4 A$ ). The overall activity score in the elevated plus-maze among vehicle-treated CRF transgenic mice was suppressed relative to vehicle-treated controls $[t(12)=1.97, p<0.05$, one-tailed] while neither 1 nor $5 \mu \mathrm{g}$ doses of $\alpha$-helical CRF 9-41 altered activity significantly relative to the respective vehicle-treated groups (Fig. $4 B$ ).

\section{Discussion}

CRF transgenic mice exhibited increased behavioral reactivity to environmental stress consistent with the known stress-enhancing effects of centrally administered CRF. This enhanced behavioral response to stress may result from a chronic state of CRF overproduction, a condition that occurs throughout de- velopment and the adult life-span of these animals. Behavioral alterations were observed in both the novel environment paradigm and the elevated plus-maze. These effects appear to be due to central CRF expression, since pretreatment with the CRF antagonist $\alpha$-helical CRF 9-41 reversed the anxiogenic-like state of the transgenic animals.

The behavior of animals in the novel setting has been shown to be sensitive to the effects of acute, central administration of CRF (Sutton et al., 1982; Sherman and Kalin, 1987). These effects are known to occur in the absence of HPA activation (D. R. Britton ct al., 1986; K. T. Britton et al., 1986a). In addition, while glucocorticoids regulate CRF in the hypothalamus, extrahypothalamic sites of CRF expression have been found to be insensitive to alterations in peripheral glucocorticoid levels (Kovacs and Mezey, 1987; Beyer et al., 1988; Swanson and Simmons, 1989; Frim et al., 1990; T. Imaki et al., 1991). The CRF transgenic animals represent an animal model wherein the transgene is not subject to the same regulatory controls of the endogenous CRF gene such as inhibition by increased levels of glucocorticoids and stimulation by catecholamines. Thus, these animals are exposed centrally to continuous CRF stimulation.

Elevated CRF expression is accompanied by a marked suppression in locomotor activity when the animals are tested in a novel environment, a finding that parallels the novelty-dependent hypoactivity following central CRF infusion. This transient reduction in exploration is probably not a motor deficit since the locomotor activity of transgenic and littermate control mice did not differ following the initial 5 min measurement interval. Furthermore, the groups did not differ over the latter part of the measurement interval in crossover frequency, a measure of ambulation from one end of the testing environment to the other, suggesting that the activity observed resulted from a normal pattern of exploration. The CRF transgenic group was relatively hypoactive during each of the six 5 min testing intervals relative to control mice, although a significant difference appeared only in the first $5 \mathrm{~min}$ interval, perhaps due to withinsession habituation to the threatening impact of an unfamiliar environment that results following $15 \mathrm{~min}$ or less of exposure (Takahashi et al., 1989). Thus, among the CRF transgenics, continuous exposure to centrally derived CRF results in a behavioral pattern similar to the anxiogenic-like effects of acute CRF administration.

In order to investigate whether in this animal model the behavioral effects of novelty could be potentiated by preexposure to a supplemental psychological stressor, the effect of a social defeat stressor upon locomotor activity in the novel environment was tested. The locomotor hypoactivity of the CRF transgenics compared with control animals subjected to the same compound stressor was more dramatic and more persistent than that induced by novelty alone. These results indicate that CRF transgenics display an exaggerated response to stress that is consistent with an increased anxiogenic behavioral state.

The behavioral effects of central CRF injection in a variety of paradigms have been shown to be "anxiogenic-like" (Dunn and Berridge, 1990). The elevated plus-maze was employed as a validated animal model of anxiety that is predictive of drug responses in humans. This test, which is based on the natural aversion of rodents to open spaces, is sensitive to the effects of both anxiolytic and anxiogenic agents in rats and mice (Pellow et al., 1985; Lister, 1987; Onaivi et al., 1990) and to the stressprotective effects of a CRF antagonist (Heinrichs et al., 1992). As in the novel environment, clear group differences were ob- 
served between the CRF transgenics and control animals using this test paradigm. The percentage of time spent on the exposed versus enclosed arms was significantly reduced among the transgenics compared with control animals, suggesting that this animal model exhibits a spontaneous anxiogenic-like state.

To test whether such increased hehavioral reactivity to environmental stress was due, in part, to the expression of CRF in these transgenics, the CRF receptor antagonist $\alpha$-helical CRF 9-41 was infused into the lateral ventricles prior to testing in the elevated plus-maze. Administration of a $5 \mu \mathrm{g}$ dose of the antagonist reversed the significant decrease in the percentage of time spent on the exposed versus enclosed arms characteristic of the transgenic mice. It has been observed before that central administration of $\alpha$-helical CRF $9-41$ in the rat attenuates stressinduced suppression of open arm exploration without altering activity on the plus-maze (Heinrichs et al., 1992). In the present experiments, this pattern of results suggests selective effects of the $\mathrm{CRF}$ antagonist on the behavioral response to stress as opposed to nonspecific changes in motor performance.

The ability of $\alpha$-helical CRF 9-41 to inhibit the action of CRF differs according to the biological action of CRF being measured (Fisher et al., 1991; Heinrichs et al., 1992). While ICV administration of this receptor antagonist results in potent inhibition of CNS effects of CRF (K. T. Britton et al., 1986b; Berridge and Dunn, 1987; Kalin et al., 1988; Fisher et al., 1991; Heinrichs et al., 1992), only weak effects by $\alpha$-helical CRF $9-41$ have been reported on CRF-induced ACTH release (Brown et al., 1989; Heinrichs et al., 1992). In the study described here, an effect of the antagonist at the level of the pituitary seems unlikely, although we cannot completely rule out this possibility since peripheral plasma ACTH levels following ICV injection of the antagonist were not determined. In view of previous studies showing that the anxiogenic behavioral effects of ICV CRF are independent of pituitary-adrenal activation (D. R. Britton et al., 1986; K. T. Britton et al., 1986a; Berridge and Dunn, 1989) and occur in experimental conditions designed to limit access of intracerebroventricularly injected CRF to the CNS (Tazi et al., 1987), it is likely that suppression of anxiogenic behavior by this CRF antagonist in the CRF transgenics is mediated centrally. In addition, although chronic elevations in ACTH or glucocorticoids during the life-span of the transgenics could contribute to their anxiogenic behavioral state, the fact that this behavioral state was reversed (as measured in the clevated plusmaze) within $5 \mathrm{~min}$ following ICV injection of the antagonist argues against effects solely mediated by these pituitary-adrenal hormones. Thus, the above findings support the hypothesis that CRF overproduction in the CNS in this animal model leads to increased anxiogenic-like behavior.

The widespread distribution of CRF expression in brains of normal animals has led to a heightened interest in the role CRF plays in regulating and integrating complex behavior (Swanson et al., 1983; Imaki et al., 1989; J. Imaki, 1991). The relative importance of CRF located in distinct brain regions is unclear, although CRF injection into specific sites, such as the locus coeruleus (Butler et al., 1990) and amygdala (Weiss et al., 1986; Liang and Lee, 1988), has been implicated in effecting distinct behavioral responses. CRF expression in the transgenic model described here is clearly elevated in a number of sites in the brain although peripheral plasma levels of CRF do not appear to be elevated (Stenzel-Poore et al., 1992). It has been reported previously that the transgenic mice displayed markedly elevated signals for CRF mRNA in nearly all areas of expression shared in common with controls. In addition, CRF transgenic mice exhibited prominent mKNA signals in some regions acknowledged as sites of CRF expression in the rat that were not detcctable in control micc, including the supraoptic and dorsomedial nuclei of the hypothalamus, lateral hypothalamic area, substantia innominata, vestibular complex, and the lateral reticular nucleus. Moreover, a number of regions not previously identified as sites of CRF gene or peptide expression in any species contained robust mRNA signals: the arcuate nucleus of the hypothalamus, the subfornical organ, lateral habenula, the granule cell layer of the dentate gyrus, the dorsal subiculum, and the deep nuclei of the cerebellum (Stenzel-Poore et al., 1992).

A number of workers have employed daily, repeated administration of CRF as a means of modeling the chronic state of CRF activation reported to accompany psychopathology in human clinical populations (Hotta, 1991). By following this course for several days or weeks one can observe diminished weight gain, hypogonadism, and persistent HPA axis activation that parallel the pattern of psychiatric symptomatology during depression or anorexia nervosa. These findings are supported by the present data in which animals with an intrinsic overproduction of CRF exhibit unprovoked hyper-reactivity to environmental stressors. Furthermore, while these animals have a Cushing's-like phenotype associated with glucocorticoid excess, the present anxiogenic state may be attributed to neurotropic actions of CRF within the brain since the reduction in exploratory behavior in response to environmental stress of the transgenic mice was reversed with a centrally administered CRF receptor antagonist. Hence, this new animal model is well suited for testing neurogenic hypotheses in the pathogenesis of human psychopathology.

\section{References}

Berridge CW, Dunn AJ (1987) A corticotropin-releasing factor antagonist reverses the stress-induced changes of exploratory behavior in mice. Horm Behav 21:393-401.

Berridge CW, Dunn AJ (1989) CRF and restraint-stress decrease ex ploratory behavior in hypophysectomized mice. Pharmacol Biochem Behav 34:517-519.

Beyer HS, Matta SG, Sharp BM (1988) Regulation of the messenger ribonucleic acid for corticotropin-releasing factor in the paraventricular nuclei and other brain sites of the rat. Endocrinology 123:21172123.

Britton DR, Varela M, Garcia A, Rosenthal M (1986) Dexamethasone suppresses pituitary-adrenal but not behavioral effects of centrally administered CRF. Life Sci 38:211-216.

Britton KT, Lee G, Dana R, Risch SC, Koob GF (1986a) Activating and 'anxiogenic' effects of corticotropin releasing factor are not inhibited by blockade of the pituitary-adrenal system with dexamethasone. Life Sci 39:1281-1286.

Britton KT, Lee G, Vale W, Rivier J, Koob GF (1986b) Corticotropin releasing factor (CRF) receptor antagonist blocks activating and 'anxiogenic' action of CRF in the rat. Brain Res 369:303-306.

Brown MR, Fisher LA (1983) Central nervous system effects of corticotropin releasing factor in the dog. Brain Res 280:75-79.

Brown MR, Gray TS, Fisher LA (1986) Corticotropin releasing factor receptor antagonist: effects on the autonomic nervous and cardiovascular function. Regul Pept 16:321-329.

Brown MR, Carver-Moore K, Gray TS, Rivier C (1989) Thryotropinreleasing factor-induced adrenocorticotropin secretion is mediated by corticotropin-releasing factor. Endocrinology 125:2558-2562.

Butler PD, Weiss JM, Stout JC, Nemeroff CB (1990) Corticotropinreleasing factor produces fear-enhancing and behavioral activating effects following infusion into the locus coeruleus. J Neurosci 10:176183.

DeNoto FM, Moore DD, Goodman HM (1981) Human growth hor- 
mone DNA sequence and mRNA structure: possible alternative splicing. Nucleic Acids Res 9:3719-3730.

Dunn AJ, Berridge CW (1990) Physiological and behavioral responses to corticotropin-releasing factor administration: is CRF a mediator of anxiety or stress responses? Brain Res Rev 15:71-100.

Fabbri A, Tinajero JC, Dufau ML (1990) Corticotropin-releasing factor is produced by rat Leydig cells and has a major anti-reproductive role in the testis. Endocrinology 127:1541-1543.

Fisher L, Rivier C, Rivier J, Brown M (1991) Differential antagonist activity of $\alpha$-helical corticotropin-releasing factor 9-41 in three binassay systems. Endocrinology 129:1312-1316.

Frim DM, Robinson BG, Pasieka KB, Majoub JA (1990) Differential regulation of corticotropin-releasing hormone mRNA in rat brain. Am J Physiol 258:E686-E692.

Gold PW, Goodwin FK, Chrousos GP (1988a) Clinical and biochemical manifestations of depression. N Engl J Med 319:413-420.

Gold PW, Pigott TA, Kling MA, Kalogeras K, Chrousos GP (1988b) Basic and clinical studies with corticotropin-releasing hormone. Psychiatr Clin N Am 11:327-335.

Heinrichs SC, Merlo-Pich E, Kiczek KA, Britton KT, Koob GF (1992) Corticotropin-releasing factor antagonist reduces emotionality in socially defeated rats via direct neurotropic action. Brain Res 581:190197.

Holsboer F, Bardeleben UV, Gerken A, Stalla GK, Muller OA (1984) Blunted corticotropin and normal cortisol response to human corticotropin-releasing factor in depression. N Engl J Med 311:1127.

Hotta M (1991) The effects of chronic central administration of corticotropin-releasing factor on food intake, body weight and hypothalamic-pituitary-adrenocortical hormones. Life Sci 48:1483-1491.

Imaki J, Imaki T, Vale W, Sawchenko P (1991) Distribution of corticotropin-releasing factor mRNA and immunoreactivity in the central auditory system of the rat. Brain Res 547:28-36.

Imaki T, Nahon JL, Sawchenko PE, Vale W (1989) Widespread expression of corticotropin-releasing factor messenger RNA and immunoreactivity in the rat olfactory bulb. Brain Res 496:35-44.

Imaki T, Nahan JL, Rivier C, Sawchenko PE, Vale W (1991) Differential regulation of corticotropin-releasing factor mRNA in rat brain regions by glucocorticoids and stress. J Neurosci 11:585-599.

Kalin NH, Sherman JE, Takahashi LK (1988) Antagonism of endogenous CRH systems attenuates stress-induced freezing behavior in rats. Brain Rcs 457:130-135.

Kathol RG, Noyes R, Lopez A (1988) Similarities in hypothalamicpituitary-adrenal axis activity between patients with panic disorder and those experiencing external stress. Psychiatr Clin N Am 11:335348.

Kaye WH, Gwirtsman HE, George DT, Ebert MH, Jimerson DC, Tomai TP, Chrousos GP, Gold PW (1987) Elevated cerebrospinal fluid levels of immunoreactive corticotropin-releasing hormone in anorexia nervosa: relation to state of nutrition, adrenal function and intensity of depression. J Clin Endocrinol Metab 64:203-208.

Kling MA, Roy A, Doran AR, Calabrese JR, Rubinow DR, Whifield HJ, May C, Post RM, Chrousos GP, Gold PW (1991) Cerebrospinal fluid immunoreactive corticotropin-releasing hormone and adrenocotropin secretion in Cushing's disease and major depression: potential clinical implications. J Clin Endocrinol Metab 72:260-271.

Kovacs K, Mezey E (1987) Dexamethasome inhibits corticotropinreleasing factor gene expression in the rat paraventricular nucleus. Neuroendocrinology 46:365-368.

Liang KC, Lee EHY (1988) Intra-amygdala injections of corticotropin releasing factor facilitate inhibitory avoidance learning and reduce exploratory behavior in rats. Psychopharmacology 96:232-236.

Lister RG (1987) The use of a plus-maze to measure anxiety in the mouse. Psychopharmacology 92:180-185.

Morely JE, Levine AS (1982) Corticotropin-releasing factor, grooming and ingestive behavior. Life Sci 31:1459-1464.

Nemeroff CB (1988) The role of corticotropin-releasing factor in the pathogenesis of major depression. Pharmacopsychiatry 21:76-82.

Nemeroff CB, Wiederlov E, Bissette B, Walleus H, Karlsson I, Eklund
K, Kilts CD, Loosen PT, Vale W (1984) Elevated concentrations of CSF corticotropin-releasing factor-like immunoreactivity in depressed patients. Science 226:1342-1344.

Onaivi ES, Green MR, Martin BR (1990) Pharmacological characterization of cannaboids in the elevated plus maze. J Pharmacol Exp Ther 253:1002-1009.

Palmiter RD, Norstede G, Gelinas RE, Hammer RE, Brinster RL (1983) Metallothionein-human GH fusion genes stimulate growth of mice. Science 222:809-814.

Pellow S, Chopin P, File SE, Briley M (1985) Validation of open: closed arm entries in an elevated plus-maze as a measure of anxiety in the rat. J Neurosci Methods 14:149-167.

Pich EM, Heinrich SC, Rivier C, Miczek KA, Fisher DA, Koob GF (1993) Blockade of pituitary-adrenal axis activation induced by peripheral immunoneutralization of corticotropin-releasing factor does not affect the behavioral response to social defeat stress in rats. Psychoneuroendocrinology 18:495-507.

Rivier C, Rivier J, Vale W (1986) Stress-induced inhibition of reproductive functions: role of endogenous corticotropin-releasing factor. Science 231:607-609.

Rivier J, Rivier C, Vale W (1984) Synthetic competitive antagonists of corticotropin-releasing factor: effect on ACTH secretion in the rat. Science 224:889-891.

Roy-Byrne PP, Uhde TW, Post RM, Gallucci W, Chrousos GP, Gold PW (1986) The corticotropin-releasing hormone stimulation test in patients with panic disorder. Am J Psychiatry 143:896-899.

Sherman JE, Kalin NH (1987) The effects of ICV-CRH on noveltyinduced behavior. Pharmacol Biochem Behav 26:699-703.

Sirinathsinghji DJS, Rees LH, Rivier J, Vale W (1983) Corticotropinreleasing factor is a potent inhibitor of sexual receptivity in the female rat. Nature 305:232-235.

Stenzel-Poore MP, Cameron VA, Vaughan J, Sawchenko PE, Vale W (1992) Development of Cushing's syndrome in corticotropin-releasing factor transgenic mice. Endocrinology 130:3378-3386.

Stephens RL, Yang H, Rivier J, Tache Y (1988) Intracisternal injection of CRF antagonist blocks surgical stress-induced inhibition of gastric secretion in the rat. Peptides 9:1067-1070.

Suda T, Tomori N, Tozawa F, Demura H, Shizume K, Mouri T, Miura $Y$, Sasano N (1984) Immunoreactive corticotropin-releasing factor in human hypothalamus, adrenal, lung cancer and pheochromocytoma. J Clin Endocrinol Metab 58:919-924.

Sutton RE, Koob GF, Moal ML, Rivier J, Vale W (1982) Corticotropin releasing factor produces behavioural activation in rats. Nature 297: 331-333.

Swanson LW, Simmons DM (1989) Differential steroid hormone and neural influences on peptide $m$ RNA levels in CRH cells of the paraventricular nucleus: a hybridization histochemical study in the rat. J Comp Neurol 285:413-435.

Swanson LW, Sawchenko PE, Rivier J, Vale WW (1983) Organization of ovine corticotropin-releasing factor immunoreactive cells and fibers in the rat brain: an immunohistochemical study. Neuroendocrinology $36: 165-186$.

Takahashi LK, Kalin NH, Burgt JAV, Sherman JE (1989) Corticotropin-releasing factor modulates defensive-withdrawal and exploratory behavior in rats. Behav Neurosci 103:648-654.

Tazi A, Swerdlow NR, LeMoal M, Rivier J, Vale W, Koob GF (1987) Behavioral activation by CRF: evidence for the involvement of the ventral forebrain. Life Sci 41:41-49.

Thompson RC, Seasholtz AF, Herbert E (1987) Rat corticotropinreleasing hormone gene: sequence and tissue-specific expression. Mol Endocrinol 1:363-370.

Vale W, Speiss J, Rivier C, Rivier J (1981) Characterization of a 41 residue ovine hypothalamic peptide that stimulates secretion of corticotropin and $\beta$-endorphin. Science 213:1394-1397.

Weiss SRB, Post RM, Gold PW, Chrousos G, Sullivan TL, Walker D, Pert A (1986) CRF-induced seizures and behavior: interaction with amygdala kindling. Brain Res 372:345-351. 